\title{
Some nanotechnology risks
}

\author{
J. A. Donovan \\ University of Massachusetts at Amherst, USA
}

\begin{abstract}
By analogy with known toxins (pollutants, quartz, and asbestos) some nanomatter may be toxic. Nanomatter is formed by manipulating atoms and molecules into new, useful materials that are on the same size scale as virus cells. The properties of nanomatter differ from macromatter with the same chemistry, and depend on its size (two of the reasons for all the excitement). Some nanomatter already exists from natural processes, but engineered nanomatter may (probably will) change our lives more than the industrial revolution. However, because these are new materials their properties and their interaction with the environment, and their effect on health are unknown. What is known by analogy and the few toxicology reports on nanomatter will be reviewed. Because of the significant potential benefits and equally significant potential risks the public needs to be informed and involved in the policy discussions concerning nanotechnology.

Keywords: nanotechnology, benefits and risks, size dependence, societial effects.
\end{abstract}

\section{Introduction}

Nanotech (NT) promises to change the way we live. How? By making things on the scale of atoms and molecules and exploiting their properties. Governments, companies, and venture capitalists throughout the world, big and small, are pouring money into nanoscience and NT. In 2004 funding of nano research and development was $\$ 8.6$ billion [1] most of it coming from the governments of at least 30 countries. The U.S. in 2005 will spend about $\$ 2.5$ bill compared to $\$ 1.6$ bill in 2004. The contribution of the U.S. government in 2005 will be almost $\$ 1$ billion [2]. The world wide annual industrial production of nanoproducts in 1015 years is estimated to be greater than $\$ 1$ trillion, and will require about 2 
million NT workers [3]. Is it worth it? Will the positive effects outweigh the negative?

NT promises, according to its supporters, to radically transform the treatment of cancer, increase the efficiency of electronic devices such as solar cells, clean up the environment, enhance food supply etc. To date these are promises, but there are nanoproducts, some old some new, in the stores: tires and photocopier toner, wrinkle and stain resistant fabrics, reinforced tennis rackets, tennis balls that do not loose their bounce, sunscreen and ultra-violet screening, anti-bacterial and medical applications that incorporate nanoparticles (NP), cosmetic products, joint cream that professional athletes are using, etc. These incrementally improved products are just the beginning. Eventually disruptive technologies (technologies that displace older technologies) will emerge, therefore it is important for the scientist, engineer and layperson to begin to understand NT. It is too early to predict how disruptive NT will be, but not too early to be concerned about how it will affect our health, environment, and safety, economy, security, etc. Will there be a backlash, like occurred with genetically modified food, biotechnology, and nuclear energy? The best and only way to avoid such a backlash is to have open discussion, open literature, open procedures that the public can study and understand and choose to support or not to.

\section{Nanotechnology and society}

The chosen assumption of the body politic in the past has been that science and engineering have been good for society; recently this assumption has been challenged, for example genetically modified food, cloning, stem cell research, wind energy, etc. As pointed out recently in SCIENCE [4] that many of these areas of research and the technology based on it clash with certain human beliefs and values. NT raises issues that challenge some of these human values and health issues. First is the toxicity of NP, with little data available the issue is unresolved. The second concerns of the relationship of between man and nature, because of the potential to manipulate life at the nanoscale it probably will challenge traditional values. These concerns and other similar ones raise questions for the funding agencies and society.

Michael Crichton in his new book, State of Fear [5] writes, "The intermixing of science and politics is a bad combination, with a bad history" [6]. However, there is no way for NT and politics not to mix because it's funding is mostly from taxes. In the future industrial support will grow and make a more significant contribution than now. This direct and strong link with taxes gives the public the right and responsibility to influence the future of NT.

State of Fear was not about NT (but about climate change). His previous book, Prey [7] focused on "nanobots", self-replicating nano-scale machines, which get out of control. It alerted and alarmed some readers, and prompted discussion of the benefits and the risks and the responsibility of developing these technologies. Prey is science fiction that concerns the clash of technology with human nature. This is one way for the public to get information about NT, but if it is the primary way it could polarize the public against NT. 
Recent surveys in the U.S. and U.K. found that between 10 and 20 per cent of the population had heard of NT. These 10 to 20 percent have high hopes that it will cure disease, but fear that it will lead to a loss of privacy. They are not much concerned that nanobots will take over the world. But, they worry the most that industry will not be honest about the risks to human health [8]. To avoid this mistrust from developing more people need to become involved in the public discussion of NT. As NT becomes better known through the commercial products based on NT the risk to NT is misunderstanding. It is important that the public be openly informed about the positive contribution that it will make to our and our children's lives. But, it is equally important that the public be informed about the risks of NT. NT will not be successful by only doing good engineering research [9]. Therefore, the US government has started funding significant research on the risks of nanoresearch to the health, environment and security. And, it intends to communicate this information with the public.

\section{Simple Introduction to Nanoscience}

To begin to understand and appreciate the benefits and risks of NT it is necessary to know that we are talking about particles or aggregates of matter that are between 1 and 100 nanometers, or $10^{-9}$ to $10^{-7}$ meters. That is the length of 10 aligned hydrogen or four gold atoms up to the diameter of a virus. So these are small particles, in fact so small that the number of atoms on the surface is comparable to the number in the total particle. For example, consider a gold particle: with a diameter of $1.3 \mathrm{~nm}$ would contain about 64 atoms and all the atoms would be on the surface. This solid particle would melt at about $200{ }^{\circ} \mathrm{C}$. The normal melting point of bulk gold is $1064.4{ }^{\circ} \mathrm{C}$.

The atoms, of any size solid, that are on the surface have more energy than atoms that are in the interior of the particle. This is why liquid drops tend to form spheres to minimize the surface energy by minimizing the ratio of surface area to bulk volume. Because NP have a large ratio of surface atoms to bulk atoms, they are high energy particles. Macroscopic gold is one of the most inert elements known; but when the particles are less than $5 \mathrm{~nm}$ in diameter gold is a catalyst, which depends on a high energy surface to interact with the reacting species [10]. The melting point of this $5 \mathrm{~nm}$ particle would be about $830^{\circ} \mathrm{C}$.

Another property of the gold particle that changes as a function of size is color: $100 \mathrm{~nm}$ gold particles appear golden, but $50 \mathrm{~nm}$ particles appear green, and if they were only $25 \mathrm{~nm}$ they would be red.

The above description highlights two important characteristics of nanomaterials: 1) they are high energy, highly reactive particles, and 2) their properties are a function of their size. Only their melting point and color were described, but most of their properties such as electrical, magnetic and mechanical are functions of their size. This is the difference between macro and nano materials: the properties of macro materials do not change with size, those of nano do. Therefore, nanomaterials are new materials with different properties than their macro equivalent with the same chemistry. Many nanomaterials, according to today's nomenclature, have been around for years. The gold 
particles described above were used to make stained glass, and vehicle tires are black because they contain manufactured NP of carbon black. They also occur naturally from fires, in the casein micelles in milk, wear debris from tires, and from vehicle exhaust. We have been living with NP for a very long time, but what is different is that new engineered nanoparticles are being made in many laboratories and many different countries. It is estimated that about 130 nanobased products have been introduced to the market. So the potential for exposure to nanoparticles, in the laboratory or plant and in public places will increase significantly in the near future.

\section{Risks}

Because our knowledge is insufficient a formal risk assessment is not possible. To fill in the knowledge gaps a new discipline: nanotoxicology is developing [11] and a new scientific journal, Nanotoxicology, will begin publication in the UK this summer. What do we know?

The current assumption is that nanotechnologies based on free NP, that can become airborne, are the potential, imminent threat. NP that are dispersed in a liquid, for example, colloids are included since the liquid may evaporate and the NP become airborne. NP that are fixed to a surface or in a solid matrix have a lower priority. However, as NT develops the same questions need to be asked as for free NP.

Natural or biological nanosystems, such as viruses are abundant in nature, and the cellular processes are nanoscale processes. Nanobiotechnology genetically, atomically or molecularly modifies these systems or processes, or in other words manipulates life at the nanoscale; at the moment these systems are not receiving the attention they deserve, but they will as nanotoxicology matures.

Nanosystems, built up by self assembly (development of three dimensional periodic arrays such as crystals, folding of proteins, the pairing of DNA, etc.) can mimic natural systems, and can be self-replicating. The current assumption, with good basis, is that these built up n-systems will require 5-10 years more development and can be controlled, so for the time being higher priority is being put on free NP. But, eventually more safety research will have to be done to conceive, develop, understand, access their risk, and control these selfreplicating systems.

The research on air pollution is relevant to free NP; this work initiated when the primary cause of 4000 deaths in London in 1952 was attributed to smog. Smog is a high concentration of particles in the nanometer size range from combustion processes, fossil fuel power plants, incinerators, diesel engines, etc. This research showed that ultrafine particles caused the increased mortality, and non-toxic substances when on the order of nanometers may cause a toxic response [12]. Finer particles have a larger percentage of surface sites (higher energy) that can attach other toxic atoms or molecules, and serve as transport agents. They are generally more reactive and can produce free radicals that damage tissue. 
Studies concerned with the effect of the inhalation of quartz dust demonstrated that their toxicity is related to the surface area of the particles and their surface activity. The toxicity of asbestos depends on the length and diameter, and surface activity of the particle. With both quartz and asbestos the harmful affects depend on the dose. All of us have some quartz and asbestos in our lungs, but they become toxic only after the accumulation of a critical dose [13].

Research continues to try to identify the relative contribution of surface area and surface activity. There is no generally accepted metric to measure dose because the mechanisms of how the fine particles cause respiratory and cardiovascular problems are not well understood. However, researches in nanotoxicology agree that the toxicity of nanomaterials, for which there is no accepted standard for quality and purity, cannot be based on the toxicity of bulk materials of the same chemistry.

Eva Oberdorster reported recently at the annual meeting of the American Chemical Society that carbon NP, buckyballs or fullerenes, could damage the cell membranes of the brains of large mouth bass [14]. The water fleas were also killed by the addition of the buckyballs to the water. Buckyballs are one of the NP receiving a lot of the attention of nanoscientists. They are made up of only carbon atoms that form a hollow structure that resembles a soccer ball. They are believed to have applications for drug delivery, environmental remediation, and in cosmetics. Also, it was reported by V. Colvin [15] that $1.5 \mathrm{ppm}$ of buckyballs in water killed one-half of E-coli bacteria that were present. The mechanisms and implications of these results have not been worked out.

These buckyballs and other carbon NP have been around for a while: they were found in an ice core 10,000 years old indicating their natural existence [16]. These same researches showed that carbon nanotubes, similar to buckyballs, are produced by methane combustion sources: kitchen gas stove tops, furnaces, power plants, etc. What is different is that with the manufacture of NP their concentration in the environment probably will become much higher. This means that the dose the population could receive might be much higher.

Gunter Oberdorster, professor of Toxicology at the University of Rochester, has been studying how the body interacts with ultrafine particles for years focusing on smog. Recently he has studied how NP accumulate, therefore they must be able to easily move which is not true for larger particles, in the cavities, lungs and brains of rats, and worries if this could lead to brain damage or harmful inflammation [17]. He is developing a model to predict the toxicity of NP. This is a significant scientific challenge because the chemical (and other) properties are a function of their size. This will not be the evolution of a model, but the creation of a new model for new materials, that will require new information and scientific understanding.

A recently published paper by Lam et al. [18] concluded that carbon nanotubes can be more toxic than quartz, and that toxicity of NP cannot be extrapolated from existing data for particles of similar chemistry. And, a paper by Warheit et al. [19] supports this conclusion. In addition its data suggest that 
the pulmonary toxicity, caused by carbon NP, is by a new mechanism, not observed before with other toxic dusts.

Preliminary work by one of the UK's leading toxicologists, Howard [20] suggests that gold nanoparticles can move from mother to the fetus by passing through the placenta. The mother rat was injected with gold particles, and then the fetus was examined for the presence of gold particles. Dark particles were observed but they have not been identified as gold particles.

Zinc oxide and titanium oxide are both used in some kinds of sunscreens and cosmetics. And, a coat of titanium oxide about $15 \mathrm{~nm}$ thick is placed on window glass and the glass becomes "self-cleaning." The oxide absorbs the sunlight, produces a photocatalytic reaction that breaks down the dirt and it washes off with the next rain or by being rinsed with water. The adsorption of the sunlight is one of the reasons that they are added to cosmetics or sunscreens. If the NP oxide is adsorbed into the skin cells, how will the particles affect the health of the cells if they are exposed to light? The answer is unknown, and the related question: Do NP get adsorbed by the skin? has not been answered. There is concern that NP could be adsorbed by injured skin and some data that they can be preferentially adsorbed at hair follicles [21], but there is no data showing adverse effects of exposure to NP.

One of the big hopes for NT is improved drug delivery and disease diagnoses. One of the NP considered for this is a cadmium selenide quantum dot that might segregate to diseased tissue, and allow identification of this tissue. However, a recent paper suggests [22] that the dots are soluble and the released cadmium would be poisonous. More work is required on its toxicity and great caution before initiating tests with humans.

Finally, how about our food supply? Some people claim that molecular food manufacturing will provide unlimited food, without farms, and without farmers. We are not there yet. The earliest applications will come with food packaging and sensors, which determine the quality of the contained food [23].

For example, it has been a long time goal to have plastic beer bottles. Plastic bottles fail because oxygen diffuses through the container spoiling the beer. Reinforcement with nano-clay particles makes the bottle stronger, but more importantly traps the oxygen (slows its transport) and increases the shelf life so that it is feasible to package beer in plastic bottles.

Other nano-additives are already available and being sold. The advantages of these additives are that they are adsorbed more easily by the body and they have a longer shelf life. Are they safe? No body knows. Do you know if your food contains nano-additives? No; because there are no requirements to list nanoingredients on the label.

\section{Summary}

NT will revolutionize our life, even if only some of the claims come true. But, NT is based on new, manufactured materials that have properties radically different from normal sized materials. Therefore, a hazards analysis cannot be done because the necessary database does not exist. However, there is enough 
data to know that great caution is necessary with regard to NP in the environment. The immediate goal of NT should be to start with the Recommendations of the Royal Society, their report [13] is the most thorough available. Or in brief 1) develop a technological basis for formal and complete safety analysis, and 2) develop better understanding of the nanostate as a basis for the engineering design of nanoproducts. This must include an open information policy so the public knows the good and bad of NT, and develops trust with this new exciting technology.

\section{References}

[1] Loder, N., Small Wonders, The Economist, Jan. 1, 2005.

[2] Giles, J., Growing nanotech trade hit by questions over quality, Nature, 432, 791, 2004.

[3] Roco, M.C. International Strategy for Nanotechnology J. of Nanoparticle Research, 3, 353-360, 2001.

[4] Leshner, A. I., Where Science Meets Society, Science, 302, 815, February $11,2005$.

[5] Creichton, M., State of Fear, HarperCollins, New York, 2004.

[6] Hotting Up, The Economist, 73, February 5, 2005.

[7] Creichton, M., Prey, HarperCollins, New York, 2002.

[8] Cobb, M. D. \& Macoubrie, J., Public Perceptions About Nanotechnology: Risks, Benefits and Trust. J. of Nanoparaticle Research, 6, 395-405, 2004.

[9] Roco, M. C., Broader Societal Issues of Nanotechnology. J. of Nanoparticle Research, 5, 181-189, 2003.

[10] Cortie, M. B. \& van der Lingen, E., Material Forum, 26, 1-14, 2002.

[11] Donaldson, K., Stone, V., Tran, C.L. Kreyling, W. \& Borm, P. J. A., Nanotoxicology, Occupational Environmental Medicine, 61,727-728, 2004.

[12] Donaldson, K., Stone, V., Clouter, A., Renwick, L. \& MacNee, W. Ultrafine Particles, Occup. Environ. Med. 58, 211-216, 2001.

[13] Nanoscience and Nanotechnologies, The Royal Society and the Royal w, Academy of Engineering, 36, July 2004March 30, 2004.

[14] Service, R. F., Buckyballs Bad for Fish, Science

[15] Service, R. F., Nanotechnology Grows Up, Science, 304, 1732-1734, June $18,2004$.

[16] Murr, L. E., Soto, K.F., Esquivel, E.V., Bang, J.J., Guerrero, P.A., Lopez, D.A., \& Ramirez, D.A., Carbon Nanotubes and Other Fullerene-Related Nanocrystals in the Environment, JOM, 56, 28-31, 2004.

[17] Taylor, P., Tiny Tech Could Be Big Health Problem, DrugResearcher.com, August 4, 2004

[18] Lam, C-W, James, J. T., McCluskey, R. \& Hunter, R. L., Pulmonary Toxicity of Single-Wall Carbon Nanotubes in Mice...Toxicological Sciences, 77, 126-134, 2004. 
130 Environmental Health Risk II

[19] Warheit, D. B., Laurence, B. R., Reed, L. L., Roach, D.H., Reynolds, G.A. M., \& Webb, T. R., Comparative Pulmonary Toxicity Assessment of Single-wall Carbon Nanotubes in Rats, Toxicological Sciences, 77, $117-$ 125, 2004.

[20] Howard, V., British Scientist: Nanoparticles Might Move From Mom to Fetus, Smalltimes, Jan. 14, 2004.

[21] Shim, J., Seok Kang, H., Park, W. -S., Han, S.-h., Kim, J., \&Chang, I. S., Transdermal Delivery of Mixnoxidil With Block Copolymer Nanoparticles, 97, 477-484, 2004.

[22] Mullins, J., Safety Concerns Over Injectable Quantum Dots, New Scientist, 181, 10, February 28, 2004.

[23] The ETC Group, Down on the Farm, November 2004. 